\title{
The Club Approach: A Gateway to Effective Climate Co-operation?
}

\author{
JON HOVI, DETLEF F. SPRINZ, HÅKON SÆLEN AND ARILD UNDERDAL*
}

\begin{abstract}
Although the Paris Agreement arguably made some progress, interest in supplementary approaches to climate change co-operation persist. This article examines the conditions under which a climate club might emerge and grow. Using agent-based simulations, it shows that even with less than a handful of major actors as initial members, a club can eventually reduce global emissions effectively. To succeed, a club must be initiated by the 'right' constellation of enthusiastic actors, offer sufficiently large incentives for reluctant countries and be reasonably unconstrained by conflicts between members over issues beyond climate change. A climate club is particularly likely to persist and grow if initiated by the United States and the European Union. The combination of club-good benefits and conditional commitments can produce broad participation under many conditions.
\end{abstract}

Keywords: UNFCCC; climate change co-operation; climate clubs; club goods; conditional commitments; agent-based models

\section{'So far, there has been no club that has brought about transformational change'.}

The global negotiations under the United Nations Framework Convention on Climate Change (UNFCCC) have thus far had only limited success in terms of producing an effective agreement for climate change mitigation. Only thirty-six countries - responsible for less than 20 per cent of global emissions - completed Kyoto 1 (2008-12) with binding emissions reduction or limitation commitments. In Kyoto 2 (2013-20), even fewer countries - responsible for an even smaller share of global emissions - participate with binding commitments. The 2015 Paris Agreement is legally binding and commendably includes 'contributions' from nearly all states. However, these contributions are specified voluntarily ('nationally determined') and are neither legally binding nor subject to any sanctions for non-compliance. Even if we assume that Paris will nevertheless achieve full compliance, the current nationally determined contributions (NDCs) will take us only part of the distance toward the very ambitious $2^{\circ} \mathrm{C}$ (or even $1.5^{\circ}$ ) goal. $^{2}$ Finally, it remains uncertain whether the Paris Agreement's dynamic mechanisms - a stringent collective temperature target, a periodic global 'stocktake', a peer-review mechanism aimed at fostering compliance through naming and shaming, and gradually increasing NDC ambitions - will work fast enough to 'prevent dangerous anthropogenic interference with the climate system'. ${ }^{3}$

\footnotetext{
* Department of Political Science, University of Oslo, Norway (email: jon.hovi@stv.uio.no); Potsdam Institute of Climate Research, Potsdam, Germany and Department of Economic and Social Sciences, University of Potsdam (email: dsp@pik-potsdam.de); Department of Political Science, University of Oslo and Cicero - Centre of International Climate and Environmental Research, Oslo (emails: hakon.salen@ cicero.oslo. no, arild.underdal@stv.uio.no). Data replication sets are available at http://dataverse.harvard.edu/dataverse/ BJPolS and online appendices are available at https://doi.org/10.1017/S0007123416000788.

1 Morgan, Messner, and Schellnhuber 2014.

2 UNFCCC 2015.

3 UNFCCC 1992, Article 2. Available from http://unfccc.int/essential_background/convention/items/6036. php, accessed 19 November 2016.
} 
Scholars, environmentalists and policy makers alike therefore continue to consider supplementary climate co-operation approaches. One option is the 'club' approach, whereby a climate club initiated by 'enthusiastic countries' tries to induce 'reluctant countries' to follow suit. ${ }^{4}$ For the purposes of this article, we define a climate club as any international actor (country) group that (1) starts with fewer members than the UNFCCC has and (2) aims to cooperate on climate change mitigation.

The global impact of a group's mitigation efforts will depend on its size and on who the members are. Thus an initially small climate club's effectiveness depends on its ability to encourage deeper co-operation among club members and to attract new members. Because reducing emissions is costly, reluctant countries have an incentive to remain non-members. ${ }^{5}$ To become successful, a climate club must be able to offset this incentive.

Using an agent-based model (ABM), we study the conditions under which a small group can attract more members and thereby become more effective at reducing emissions. Thus we try to model the evolution of co-operation on a single issue (climate change mitigation) within a particular institutional context (climate clubs). We focus on which countries become club members and measure 'success' in terms of these members' aggregate share of global emissions. Finally, we examine the sensitivity of our results to alternative assumptions concerning damage costs and bilateral relationships beyond climate change (trade, affinity and militarized conflict).

Prakash and Potoski draw a useful distinction between two types of clubs. ${ }^{6}$ In 'Buchanan clubs', the production and allocation of club goods are primary goals. ${ }^{7}$ Moreover, there is no incentive for free riding: only those paying the club fee enjoy club goods due to the possibility of exclusion. ${ }^{8}$

By contrast, in 'voluntary clubs' the main goal is to produce a public good (or some other benefit that generates a positive externality) ${ }^{9}$ hence, strong incentives for free riding may exist. It follows that substantial inducements may be required to encourage membership and to motivate members to contribute more to the public good than non-members do. Climate clubs may be considered a subcategory of voluntary clubs.

We simulate how a climate club's membership might evolve, contingent on three factors. The first is which countries are enthusiastic and thus serve as initiators of the club (enthusiasts are assumed to have an intrinsic motivation to start a club). The second is whether enthusiastic countries make conditional pledges for additional emissions reductions. Finally, the third factor is the level of club-good provision.

We consider a club good consisting of a preferential trade agreement exclusively for club members. Linking climate change mitigation to trade in this way could violate the World Trade Organization's (WTO's) most-favored-nation (MFN) principle. ${ }^{10} \mathrm{We}$ see at least three possible

${ }^{4}$ Keohane, Petsonk, and Hanafi 2015; Nordhaus 2015; Stewart, Oppenheimer, and Rudyk 2013a, 2013b; Victor 2011.

${ }^{5}$ Abatement costs are often assumed to be lower in poorer countries than in richer ones. Providing a new representation of investment risks, Iyer et al. (2015) challenge this assumption.

${ }^{6}$ Prakash and Potoski 2007

7 Buchanan 1965.

${ }^{8}$ Buchanan reserves the term 'club good' for excludable goods that exhibit little or no rivalness for low to moderate consumption levels yet significant rivalness for higher consumption levels (because of congestion effects). By contrast, as used in the climate club literature, a 'club good' may or may not entail a congestion effect. It may even become gradually more beneficial with increasing participation; indeed, as we will show, a major driving force in our model is that the 'club good' scales up with club size.

${ }^{9}$ One referee argued that 'public good club' might be better than 'voluntary club'. We agree. However, in this article we stick to the latter, which is the more established term.

${ }^{10}$ The IPCC's $5^{\text {th }}$ Assessment Report provides an account of the relationship between climate policy, international co-operation and WTO regulations. See Stavins et al. 2014, 1030-5. 
options for overcoming this constraint. The first is through the GATT's Article XX(g), which permits exceptions to the MFN principle in relation to natural resource conservation. ${ }^{11}$ The second is by adding the preferential trade agreement to existing WTO provisions, in accordance with Article XXIV. The third is by WTO members creating a new MFN exception that explicitly permits discriminatory climate club trade benefits. ${ }^{12}$

The emergence of a climate club is envisioned as a complex and dynamic bottom-up process that occurs in a heterogeneous setting. ${ }^{13}$ ABMs are ideal for studying processes with these characteristics. ${ }^{14}$ Unlike game-theoretic models, which present only equilibrium outcomes, ABMs describe the emergence of co-operation explicitly. They also facilitate grounding the traits of heterogeneous model agents on empirical data. To the best of our knowledge, we have developed the first ABM of climate clubs. ${ }^{15}$

Our results suggest that even a club with fewer than a handful of major actors as initial members can grow and eventually become very effective at reducing global emissions, assuming that the club pursues an open-membership policy and provided that two conditions are met.

First, the 'right' actors must be enthusiastic. In particular, the actors initiating the club must control a sufficiently large share of global emissions and income. The United States or the European Union (EU) (but not China) can under some conditions single-handedly initiate a club that can persist and attract other members. If both were enthusiastic, the prospects for at least moderate club success would appear bright, because in our model the United States and the EU can in many cases entice China to join by appealing to its self-interest.

Secondly, the club must provide sufficiently large incentives for reluctant actors to become members. A combination of club-good benefits and conditional commitments produces broad participation under a range of conditions. Conditional commitments effectively enhance climate co-operation in the presence of club-good benefits, and vice versa.

In the next section, we briefly review the relevant research literature. In the third section, we describe our model and report our simulation results. The final section concludes.

\section{LITERATURE REVIEW}

Reviewing the recent climate club literature, Falkner argues that starting small might be advantageous in at least three ways - by facilitating dialogue and bargaining, by creating incentives for membership and by offering great powers a privileged position (thereby enhancing the legitimacy of international climate governance in their eyes). ${ }^{16}$ Focusing on incentives, and therefore being grounded in the second way, this article considers the potential for enthusiastic actors to use club goods and conditional commitments to attract members. This section identifies and discusses three main determinants of climate club success, thereby providing a basis for our simulations. First, however, we briefly review the general climate club literature. ${ }^{17}$

11 Helm, Hepburn, and Ruta 2012.

12 Gardoqui and Ramírez (2015) offer a detailed discussion of the third option, which in our view may be hard to accomplish. Considering that the need to work in small groups concerning climate arises precisely because countries disagree over this issue, it seems unlikely that all WTO members would consent to creating such a new MFN exception.

13 Victor 2011.

14 See, e.g., Miller and Page 2007.

15 Sælen (2016) presents a variation of this model focusing on side payments.

16 Falkner 2016. Gampfer (2016) finds that climate clubs need careful institutional design to be perceived as legitimate and hence to be politically feasible.

17 For recent reviews of the related literatures on repeated games and coalition games, see Hovi, Ward, and Grundig (2015) and Hovi et al. (2016). 


\section{Climate Clubs}

A well-known barrier for progress in the UNFCCC negotiations is the consensus rule, which enables determined countries to block collective decisions that are not in their interest, either single-handedly or by forming small, vocal coalitions.

To bypass this barrier, Victor suggests that co-operation should begin with small groups (or 'clubs') of enthusiastic countries and be based on a high degree of flexibility concerning the choice of policies. ${ }^{18}$ The 'backbone' of his proposal is a series of contingent offers, whereby governments outline what they are 'willing and able to do', depending on what others offer and implement. We refer to such contingent offers as 'conditional commitments'. Finally, reluctant countries should be enticed to join via 'exclusive and contingent' measures, that is, club goods (what Olson terms 'selective incentives'). ${ }^{19}$

The club approach leaves it to each country to decide whether to participate in the initiation of a climate club ('enthusiastic' country), join later or stay out, based on different calculi of optimality. Rather than relying on decision rules that may obstruct groups of countries from jointly engaging in climate change mitigation, the club approach envisions the development of a coalition of the willing. It thus allows for coalition sizes substantially smaller than required for UNFCCC consensus. Put differently, rather than potentially obstructing attempts to form a mitigation coalition, the club approach allows for bottom-up formation of coalitions based on optimality for club members.

Stewart, Oppenheimer and Rudyk present climate clubs as one of three building blocks in their proposed new strategy for global climate change mitigation. ${ }^{20}$ Unlike us, they conceive of climate clubs as Buchanan clubs (where non-climate, excludable benefits provide the primary or even the sole incentive for participation). They also propose that membership should be broadened to include transnational groups of firms in key industry sectors.

A few scholars have assessed the empirical record of actor groups that have tried to address climate change outside the UNFCCC. The evidence suggests that such groups have (thus far) been no more effective at advancing climate co-operation than the UNFCCC has been. For example, Andresen evaluates select 'exclusive alternatives' to the UNFCCC, such as the Asia-Pacific Partnership on Clean Development and Climate Change, the Major Economies Forum on Energy and Climate (MEF), the G20, and the Climate and Clean Air Coalition. ${ }^{21} \mathrm{He}$ concludes that these alternatives have largely served as 'discussion clubs' that have achieved very little in terms of actual emissions reductions. Similarly, after considering no fewer than seventeen climate clubs, Weischer, Morgan and Patel conclude that these clubs are little more than forums for political dialogue. ${ }^{22}$

\section{Which Actors Are Enthusiastic?}

A first crucial factor influencing a climate club's chances of eventually becoming successful at reducing global emissions is which actors serve as enthusiasts (club founders). What type of actors are likely to play this role?

The most plausible and effective candidates will likely be major emitters with relatively low greenhouse gas (GHG) abatement costs, relatively high damage costs or - ideally - both. ${ }^{23}$

18 Victor 2011.

19 Olson 1965.

${ }^{20}$ Stewart, Oppenheimer, and Rudyk 2013a, 2013b.

21 Andresen 2014.

${ }^{22}$ Weischer, Morgan, and Patel 2012. Note that their definition of a 'climate club' differs from ours; hence, their conclusions will not necessarily apply to 'clubs' as defined here.

${ }^{23}$ Sprinz and Vaahtoranta 1994. 
This presumption informs our simulations. We do realize, though, that even countries that meet all of these requirements need not become frontrunners. Very long time lags, measured in decades and even centuries, between mitigation measures ( costs) and environmental effects ( benefits) generate profound asymmetries in cost-benefit considerations. ${ }^{24}$ Potential club founders may therefore also be looking for short-term and private benefits. Collaboration with attractive club partners may well be the most effective way to produce such benefits (see below). Mitigation measures can also have positive domestic side effects (co-benefits), such as improved public health through reduced local pollution. Some governments rely on support from influential environmental NGOs or broader 'Baptists and Bootleggers' coalitions. ${ }^{25}$ Finally, climate change policies and practices are in some cases also guided by norms of appropriateness, in particular by distributive-fairness principles concerning responsibility ('guilt'), capacity and need. ${ }^{26}$ Therefore a comprehensive analysis of global climate change negotiations should also consider such domestic sources of 'enthusiasm'. In the simulations presented in this article, however, we limit the analysis to climate club benefits originating at the international level.

\section{Conditional Commitments}

A second factor concerns climate club members' use of conditional commitments. Several scholars have considered how followers are likely to respond to a leader taking unilateral environmental action - conditionally or unconditionally. A main finding is that unconditional unilateral action typically has zero (or even an adverse) effect on followers' emissions reductions. ${ }^{27}$ By contrast, conditional unilateral action can contribute positively under some circumstances. ${ }^{28}$ In our model, conditional unilateral club action constitutes a core element.

The 2015 Paris Agreement lets each party set its own mitigation target by submitting a so-called NDC. NDCs may contain conditional components, which could be expressed in two main ways. ${ }^{29}$ One type ('intrinsic' conditionality in Lipson's terminology) ${ }^{30}$ would link a country's own commitments to other countries' mitigation efforts. Another type ('extrinsic' conditionality) would make a country's own commitments conditional on other countries' efforts in other related policy domains, such as financial and technological support.

While extrinsic conditions are left for future research due to space constraints, our simulations consider the effect of intrinsic conditions. Some countries also used intrinsic conditions under the 2009 Copenhagen Accord. ${ }^{31}$

\section{Club Goods}

Finally, a third factor that might influence a climate club's success is whether and to what extent it provides club goods. Making countries' access to a club good conditional on their mitigation efforts constitutes a form of issue linkage. ${ }^{32}$ Club initiation and growth require that actors

24 Underdal 2010.

25 DeSombre 1995.

26 See, for example, Mattoo and Subramanian 2012.

27 See, for example, Buchholz, Haslbeck, and Sandler 1998; Hoel 1991.

28 Holtsmark 2013; Underdal et al. 2012.

29 UNFCCC 2015, paragraph 26.1.

30 Lipson 1981.

31 The Copenhagen Accord pledges are available from http://unfccc.int/resource/docs/2011/sb/eng/inf01r01.pdf (developed countries) and http://unfccc.int/resource/docs/2011/awglca14/eng/inf01.pdf (developing countries).

32 See Finus (2003) for an overview. 
expect the club to provide net benefits for them. One form of such benefits is club goods, such as preferential terms of trade or investment, joint $R \& D$ programs in renewable energy technology, access to emissions trading programs, or extension of pipelines or electricity grids to facilitate efficient use of total energy production capacity.

Some scholars find that club goods in the form of technology research and development (R\&D) can advance climate co-operation. ${ }^{33}$ However, Barrett questions their findings, arguing that several international agreements (including the Montreal Protocol) require the parties to co-operate on technology $R \& D$, yet do not encourage members to withhold the fruits of such $\mathrm{R} \& \mathrm{D}$ from non-members. A likely reason, he argues, is that doing so would be detrimental to members' self-interest. ${ }^{34}$ Similarly, club goods in the form of linkage to trade have been proposed, ${ }^{35}$ although such linkage may also be detrimental to members' self-interest. In practice, however, countries sometimes do seem to accept losses from imposing trade sanctions when they believe sanctions might serve a sufficiently important purpose. ${ }^{36}$ Moreover, it seems fully consistent with Victor's basic idea of enthusiasm to assume that enthusiastic actors might be prepared to forgo potential benefits from trade with reluctant actors that decline to join the club.

Our work is related to that of Nordhaus, ${ }^{37}$ who finds that small trade penalties on nonparticipating countries can induce an agreement with broad participation and deep emissions reductions. However, his analysis differs from ours in two important respects. First, he adopts a top-down approach in which the regime's design is already optimized to achieve high levels of participation and abatement, while we consider how co-operation might evolve from a small initial coalition. Secondly, whereas he assumes that co-operation centers on 'an international target carbon price', we assume that it centers on undertaking emissions reductions equivalent to a fixed percentage of gross domestic product (GDP). ${ }^{38}$ While a common carbon price is economically more efficient, we deem it politically less realistic.

Preferential market access - the club good we focus on in our simulations - will be more attractive the more members the club already has and the larger the economies of these members. ${ }^{39}$ In a club with many large members, market access could make a significant difference, because few alternative suppliers and buyers would remain outside. Our ABM therefore models club-good benefits as an increasing function of club size. These increasing returns, combined with cross-actor differences in cost-benefit calculus, may trigger a snowball effect, whereby reluctant actors requiring the smallest non-climatic compensation join first and help shift the cost-benefit balance for actors requiring slightly higher compensation, and so on.

To create such an effect, the club must pursue an open-membership policy, so that reluctant actors wishing to join are free to do so, provided they satisfy membership requirements. ${ }^{40}$ This condition, which is satisfied in our simulations, excludes the possibility that a group such as the EU could succeed as a climate club by increasing membership, simply because the EU would

33 Buchner et al. 2005; Carraro and Siniscalco 1997.

34 Barrett 2003, 309-10.

35 See, for example, Nordhaus 2015; Stiglitz 2006.

36 The US and EU trade sanctions against Russia provide an example.

37 Nordhaus 2015.

38 Sælen $(2016$, 918-19) discusses this assumption in more detail.

39 In this respect, preferential market access differs significantly from most other club goods. For example, preferential access to a new technology would likely become less beneficial the larger the number of other countries that have such access (because the competitive edge provided by the technology would shrink).

${ }^{40}$ WTO plurilateral agreements pursue a similar open-membership policy. For example, see the WTO Agreement on Government Procurements, Article XXIV.2. 
be unlikely to accept new members on the basis of applicants' climate policies. The same is true for most of the 'exclusive groups' considered by Andresen, such as the G20, the G8/G7 and the MEF. ${ }^{41}$

Under what conditions should we expect reluctant actors to respond positively to a climate club offering a club good? According to Weischer, Morgan and Patel, ${ }^{42}$ the club good must be significant enough to outweigh the temptation to free ride by remaining a non-member. Thus the club must control sufficient resources so that it can make membership worthwhile for reluctant actors. A second condition is that it must be credible that an actor will enjoy the club good if and only if it becomes a club member. ${ }^{43}$

The latter condition implies that compliance enforcement is essential for a climate club to become effective. We nonetheless follow the extensive game-theoretic literature on stable coalitions, drawing on d'Aspremont's two-stage model, ${ }^{44}$ by focusing on participation. Some scholars argue that participation is the binding constraint. ${ }^{45}$ Club goods' excludability significantly simplifies the policing of free riding in a climate club. ${ }^{46}$

The list of major GHG emitters indicates that at least some potentially powerful clubs might include members with strongly divergent preferences regarding the distribution of mitigation commitments. ${ }^{47}$ Some potential members' relationships - such as that between China and the United States - are also strained by geopolitical or economic conflicts. The joint statements issued by China and the United States nevertheless suggest that conflict over other issues need not prevent all forms of climate club co-operation. We conduct sensitivity tests to check the influence on our main simulation results by including exogenous stakes in our ABM simulations.

Although conditional commitments and club goods constitute the major focus of this article, we emphasize that a climate club might also generate other types of benefits. First, a club might reduce climate damage through enhanced mitigation measures (that is, through provision of the global public good itself). Secondly, benefits may come in the form of side-payment arrangements similar to existing global UNFCCC schemes (for example, the Clean Development Mechanism), whereby developed countries help fund climate-friendly measures in developing countries. Finally, benefits may come in the form of (predictable) side effects, ${ }^{48}$ such as a reduced loss of competitive edge in international markets.

\section{AGENT-BASED SIMULATIONS OF CLIMATE CLUB EMERGENCE AND GROWTH}

The theoretical discussion above has provided some general expectations concerning the conditions under which a climate club might persist and grow. Deriving more exact predictions requires a detailed analysis of every actor's cost-benefit calculations in a wide range of scenarios. Much of the data required to make such calculations are available, and although the costs and benefits of climate change mitigation are uncertain, information asymmetries do not appear particularly stark. However, because each actor's costs and benefits differ from those of

41 Andresen 2014.

42 Weischer, Morgan, and Patel 2012.

43 The same applies for conditional commitments (if any).

44 d'Aspremont et al. 1983.

45 See, for example, Barrett 2003.

46 Stewart, Oppenheimer, and Rudyk 2013a.

47 See, for example, Shum 2014. To illustrate, a club including the four largest GHG emitters would consist of China, the United States, the EU and India.

${ }^{48}$ Here, we use the term side payments for deliberately designed incentives and side effects for unintended consequences of mitigation measures. 
others (and depend on every other actor's choices), the interaction becomes complex even when based on quite simple input assumptions. Analytical models would hardly be able to incorporate all relevant data, so numerical simulations can enhance our understanding of the emergence and growth of climate clubs.

Our ABM aims to capture select essential climate club features, while leaving out many complicating real-world factors. The basic decision is binary: each actor must decide whether to join a climate club. We assume that any actor that wishes to join is free to do so, provided it satisfies the membership criterion - that each member must implement mitigation measures worth at least 1 per cent of its GDP. Thus the model considers one specific form of climate club.

We also initially make the simplifying assumption that decisions concerning climate co-operation are based on the merits of that issue area only. However, we relax this assumption in the sensitivity analysis.

The model is a one-shot sequential game with an indefinite number of stages. All costs and benefits are measured in present value, and all decisions (unless revoked) are implemented instantaneously. We assume complete information. While we cannot capture all real-life challenges to international co-operation on mitigating climate change, our model provides a useful tool for systematically exploring the potential contributions of clubs to enhancing climate change mitigation.

We consider two mechanisms for club growth. First, besides undertaking mitigation - a global public good benefitting members and non-members alike - the club may produce a club good for members only. Secondly, members may offer to deepen their mitigation efforts conditional on new members joining (and thereby agreeing to spend at least 1 per cent of their GDP on mitigation). We will refer to such offers as 'conditional commitments' 49

\section{Model Description}

The online appendix provides our model's formulae and describes the model in pseudocode, thereby complementing the verbal description we offer here. The model's actors are of two types, depending on their motivation for mitigation. Reluctant actors are rational and selfinterested; hence, they will join the club if and only if joining leads to private benefits that exceed the abatement costs (1 per cent of GDP). As defined by Victor, enthusiastic actors are willing to spend their own resources on mitigation. ${ }^{50} \mathrm{We}$ assume they have an intrinsic motivation to start a club, despite that doing so entails (initial) costs. They are, in other words, willing to incur mitigation costs of 1 per cent of GDP even without any commitment by reluctant parties to follow suit.

Furthermore, enthusiastic actors will not necessarily abandon the club even if they would benefit from withdrawing unilaterally. However, even an enthusiastic actor will exit if the club - after negotiations with all reluctant actors - proves to generate lower net private benefits for the enthusiastic actor than the no-club scenario does. Thus enthusiastic actors compare the pay-off they get as a member of the club with the pay-off they would get if they left and the club

49 A potential challenge for a sub-global club is carbon leakage, which may arise through different mechanisms (Hoel 2012). Like most game-theoretic climate-coalition models, our model does not explicitly address this challenge. We expect that carbon leakage would at least initially reduce clubs' effectiveness. However, limited data make this reduction's magnitude difficult to estimate. Most estimates rely on computable equilibrium models and find leakage rates in the range of 5 per cent to 20-30 per cent (Hoel 2012; Sterner, Carbone, and Fischer 2015). Leakage decreases with club size, but also depends on other factors such as economies' openness (Böhringer, Fischer, and Rosendahl 2010).

50 Victor 2011. 
collapsed. In this respect, enthusiastic actors behave akin to the conditional co-operators modeled by Richter and Grasman and to the strong reciprocators modeled by Sælen: ${ }^{51}$ they prefer to participate conditional on a certain amount of reciprocity. If all actors were enthusiastic, mitigation would become an assurance game. Reluctant actors, by contrast, will free ride on members' mitigation as long as their pay-off outside the club is greater than their pay-off inside it. They therefore compare their pay-offs inside and outside the club holding other actors' membership constant.

Actors have three further attributes with empirically grounded values: emissions, ${ }^{52}$ GDP $^{53}$ and climate change vulnerability scores (see Table $2^{54}$ ). Complete data are available for 168 countries, accounting for 98 per cent of both global emissions and gross global product (GGP). Because we model the EU as a single actor, the model includes 141 actors.

Estimating the global costs and benefits of climate change mitigation is beyond this study's scope. Rather, we run the model for different assumptions concerning the club's impact in terms of the damage costs avoided. The input variable Global Damage expresses the assumed damage cost difference between the business-as-usual (BAU; no-club) scenario and the scenario in which all actors spend 1 per cent of their GDP to mitigate climate change (universal club participation). In the Stern review, ${ }^{55} 1$ per cent of GGP emerges as the central estimate for stabilizing atmospheric concentrations at 500-550 parts per million $\mathrm{CO}_{2}$ equivalents $\left(\mathrm{ppm} \mathrm{CO}_{2} \mathrm{e}\right.$ ). That would avoid the worst climate change impacts, which in the BAU scenario would 'equate to an average reduction in global per-capita consumption of 5 per cent, at a minimum, now and forever', the report finds. Incorporating those findings into our model is non-trivial, because the report measures costs and benefits in different units, assumes costefficient mitigation and has caused substantial academic controversy. The most recent Intergovernmental Panel on Climate Change (IPCC) report suggests that mitigation is somewhat more expensive, with annual GGP losses from stabilizing at $530-550 \mathrm{ppm} \mathrm{CO}_{2} \mathrm{e}$ starting at 0.5 per cent in 2020, rising by 1 per cent in 2030 and 2 per cent in 2050 to 4 per cent in 2100 (median estimates). ${ }^{56}$ That scenario will entail a slightly less than 40 per cent probability that warming will not exceed $2{ }^{\circ} \mathrm{C}$ above pre-industrial levels. ${ }^{57}$ The report does not monetize the benefits of stabilization, but the consequences of doing nothing seem no less grave than they did when the Stern review was conducted. It seems safe to assume that collectively spending 1 per cent of GGP on mitigation would provide substantial benefits, but that it would not suffice to achieve the $2^{\circ} \mathrm{C}$ target. In the baseline model, we set Global Damage to 3 per cent of GGP, implying that the present value of climate benefits of a global club outweighs costs by a factor of three, which is conservative compared with the Stern review. For sensitivity checks, we also present results for values of 1.5 per cent and 4.5 per cent of GGP.

When only a subset of the 141 actors participates, the climatic benefit is assumed to be a linear function of emissions covered. In particular, a club covering 50 per cent of global emissions is assumed to produce 50 per cent of the climate benefits produced by a global club. Carbon leakage (see footnote 49) would entail that such a club produces less than 50 per cent of the benefits of a global club, while increasing marginal damage costs would entail that it produces more than 50 per cent.

${ }^{51}$ Richter and Grasman 2013; Sælen 2014.

52 Global Carbon Project 2014 (2013 figures); World Resources Institute 2014 (2011 figures).

53 World Bank 2014 (2013 figures).

${ }_{55}^{54}$ Notre Dame Global Adaptation Index (NDGAIN) 2014 (2012 figures).

${ }^{55}$ Stern 2007.

${ }^{56}$ Clarke et al. 2014, 450.

${ }^{57}$ Clarke et al. 2014, 440. 
Our approach assumes governments attach some weight to future costs incurred by their citizens. In contrast, a purely myopic government would care little about future climate change impacts. Specifying costs in their present value sidesteps the difficult question about the rate at which future climate change impact costs should be discounted.

Finally, we assume that damage costs are distributed in proportion to actors' GDP and vulnerability. Because vulnerability affects damage costs, which in turn affect the incentive for club membership, vulnerability heterogeneity leads to heterogeneous incentives for membership. The model incorporates empirical data on vulnerability from the Notre Dame Global Adaptation Index, ${ }^{58}$ which allocates scores based on actors' exposure, sensitivity and adaptive capacity in eight sectors. The scores range from 0.15 (Switzerland) to 0.59 (Burundi) and are denoted $\operatorname{NDGAIN}_{i}$. Translating index scores of vulnerability into damage functions is certainly not trivial, because only limited empirical guidance is available. We use a model input variable called Vulnerability Weight, which determines the variance of the damage cost distribution across actors, while keeping constant global costs and actors' rank concerning damage costs as a percentage of GDP. Specifically, we use the following formula:

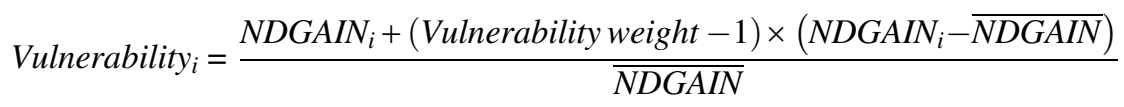

It expresses actor-specific vulnerability as the percentage loss in $\mathrm{GDP}_{\mathrm{i}}$ arising when the global loss is 1 per cent of GGP. $\overline{N D G A I N}$ is the GDP-weighted average NDGAIN score across all actors. The value of Vulnerability Weight determines how skewed damage costs are to the disadvantage of the most vulnerable. Because this skewness is highly uncertain, we analyze a wide range of possibilities. As one extreme case, we set Vulnerability Weight to 0, implying that Burundi and Switzerland suffer the same percentage reduction in GDP as a result of climate change. At the other extreme, we set Vulnerability Weight to 2, implying that Burundi suffers a reduction nineteen times greater than Switzerland does. In the baseline case, Vulnerability Weight is set to 1, implying that Burundi suffers a reduction four times greater than Switzerland does.

Damage costs, as well as all other costs and benefits, are measured in their present value, as a percentage of current GDP. Given the above definitions and assumptions, an actor's incentive to mitigate climate change depends on its vulnerability and emissions. Emissions matter, because (other things being equal) a large actor emits more GHGs than a smaller actor does and therefore causes more climate damage, including to itself.

\section{Instruments for Club Growth}

We study two instruments for club growth - club-good benefits (in the form of preferential market access for members) and conditional commitments (increased mitigation pledges in exchange for increasing membership). The model permits us to study these two instruments both separately and in combination.

Concerning club-good benefits, the model assumes that only club members benefit from the club good. Available data do not allow a precise empirical calibration of the size of such goods, but the following characteristics seem plausible: (1) benefits increase with the sum of other members' GDP, but at a decreasing rate, (2) benefits are generally less than 1 per cent of GDP (otherwise the club-good benefit would suffice to motivate membership even disregarding the

${ }^{58}$ Notre Dame Global Adaptation Index 2014. 


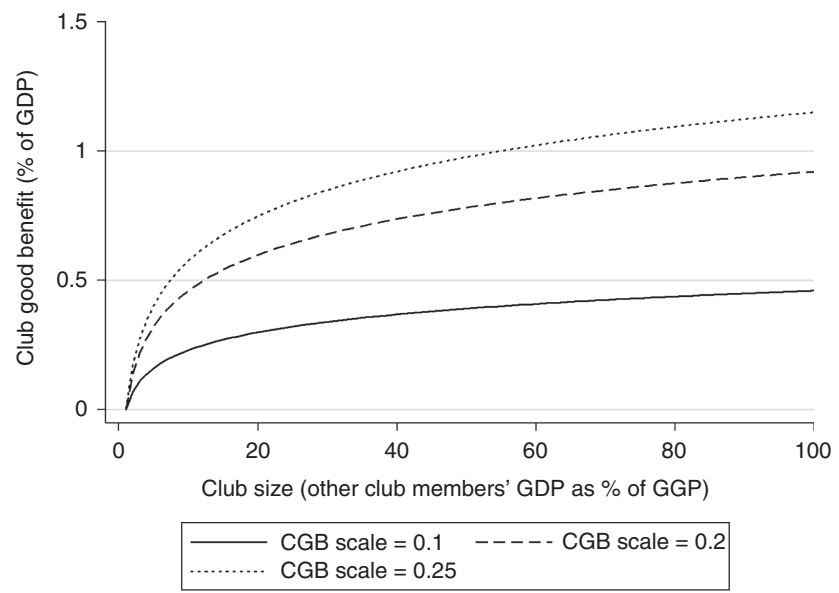

Fig. 1. Club-good benefit functions under various assumptions tested

public good produced through mitigation) and (3) benefits are comparable with estimated benefits from possible new trade deals. Such estimates do not abound, but Francois et al. estimate that a transatlantic trade and investment agreement would increase the EU's GDP by $0.3-0.5$ per cent and the United States' GDP by $0.2-0.4$ per cent. ${ }^{59}$

Taking the natural logarithm of other members' GDP achieves Point (1) (above). Point (2) suggests multiplying that logarithm by a scaling factor of about 0.2 or less and Point (3) suggests multiplying by around 0.1 . We run the model for values between 0 and 0.25 , focusing particularly on the points $0.1,0.2$ and 0.25 . Denoting this multiplier CGB Scale, we get the following equation:

$$
\text { Club benefit }{ }_{i}=C G B \text { scale } \times \ln \left(\sum_{m \neq i}^{\text {members }} G D P_{m}\right)
$$

The corresponding Club-Good Benefit functions are illustrated in Figure 1. For comparison with Francois et al.'s estimates, a club consisting of the EU and the United States would increase each member's GDP by around 0.3 per cent, 0.6 per cent and 0.75 per cent for the respective $C G B$ Scale values. A $C G B$ Scale of 0.25 hence represents very optimistic assumptions.

Turning to conditional commitments, Victor argues that pledges should not just be declarations of what an actor will do, but promises of effort conditional on what others pledge or do. ${ }^{60}$ Our model includes one specific form of such conditional commitments: it allows members to pledge a deepening of their mitigation effort if a new entrant joins the club. Because additional mitigation benefits all actors, this instrument is less targeted than a club-good benefit is. However (and unlike the offer of a club-good benefit), a conditional commitment does not require linking climate change mitigation to some other good or benefit.

In the model, a new member's entry produces benefits for existing members through reduced climate damage and (depending on other inputs chosen) an increase in the club-good benefit. Each non-member $i$ 's entry therefore benefits each member $m$ enough to compensate it for the

59 Francois et al. 2013.

60 Victor 2011. 
TABLE 1 Model Inputs Set at Initialization

\begin{tabular}{|c|c|c|c|}
\hline Input & Explanation & $\begin{array}{l}\text { Baseline model } \\
\text { values }\end{array}$ & $\begin{array}{l}\text { Sensitivity test } \\
\text { values }\end{array}$ \\
\hline $\begin{array}{l}\text { Vulnerability } \\
\text { Weight }\end{array}$ & $\begin{array}{l}\text { Degree of differentiation between } \\
\text { more and less vulnerable actors }\end{array}$ & 1 & $0 ; 2$ \\
\hline Global Damage & $\begin{array}{l}\text { The difference in global climate } \\
\text { damage costs between the business- } \\
\text { as-usual (BAU; no-club) scenario } \\
\text { and the scenario where all actors } \\
\text { spend } 1 \% \text { of their GDP to mitigate } \\
\text { climate change }\end{array}$ & $3 \%$ of GGP & $\begin{array}{l}1.5 \% \text { of GGP; } \\
4.5 \% \text { of GGP }\end{array}$ \\
\hline Enthusiasts & Which actors are 'enthusiastic'? & See Table 3 & \\
\hline CGB scale & Scaling factor for exclusive club good & $0 ; 0.1 ; 0.2 ; 0.25$ & $\begin{array}{c}0 ; 0.01 ; \ldots, \\
0.25\end{array}$ \\
\hline $\begin{array}{l}\text { Conditional } \\
\text { Commitments }\end{array}$ & Conditional commitments allowed? & Yes/No & \\
\hline
\end{tabular}

Note: the first two inputs are empirical parameters with uncertain values, included for the purpose of sensitivity analyses. The last three are characteristics of the negotiation process, and constitute the main foci of the analysis.

costs of a certain extra mitigation effort, $\Delta_{i m}$. We incorporate the increasing marginal cost per unit of emissions reductions, assuming a quadratic cost function. Hence, benefits are a concave function of $m$ 's expenditure (see Appendix Table A1). If the sum of $\Delta_{i m}$ across members would benefit $i$ enough to outweigh $i$ 's net cost of joining (taking into account its other benefits from membership), a mutually advantageous expansion is possible in which existing members increase mitigation expenditure incrementally above 1 per cent of GDP in return for the potential member $i$ committing to spend 1 per cent of its GDP, resulting in damage cost reductions that outweigh (additional) mitigation expenditure for every actor involved.

This situation amounts to an assurance game for the members. In one equilibrium, all make zero extra effort. In other equilibria, the members collectively make just enough effort to induce the potential entrant to join. This collective effort can be divided in many ways, which may give rise to internal bargaining. Because prospects for international co-operation in the face of assurance games are reasonably good, ${ }^{61}$ and because the number of club members is, at least initially, small, we assume that agreement among members will be reached, enabling the club to induce the potential entrant to join. Following a standard effort-sharing rule in the game-theoretic literature on international environmental agreements, ${ }^{62}$ we assume that each actor's extra effort is proportional to its benefit from expansion, $\Delta_{i m}$. This rule ensures the expansion makes no member worse off. In principle, members also benefit from every other member's increased expenditure, and these benefits should increase their willingness to contribute. The effect will, however, likely be weak in most cases, so we have not included it in the analysis reported here. Conditional commitments are assumed to be fully credible, a simplification that future work should seek to drop.

61 Barrett 2013.

62 See, for example, Finus 2003. 


\section{Model Steps}

The model includes (up to) three steps.

Initialization: The modeler chooses the inputs listed in Table 1.

Step 1: Enthusiastic actors join the club automatically. A reluctant actor joins if and only if the sum of its club-good benefit and its gross private benefit from reducing its own emissions exceeds the 'club fee' ( 1 per cent of GDP). First, every reluctant actor makes a preliminary decision. Additional decision rounds occur until no additional actor wants to join. Thus an actor that chose not to join in the first round can reverse its decision in a later round.

Step 2: (included only if conditional commitments are allowed): The model calculates the benefit to each member of each non-member's potential entry. If the total benefit to the club of a specific reluctant actor's entry enables the club to increase mitigation commitments enough to induce the non-member to join, a deal based on conditional commitments is struck. This step is repeated until no more mutually advantageous deals can be made, following the same logic as in Step 1. If there is a club good, its size increases as the club expands, so a non-member that initially declined might later find it in its best interest to join even absent additional mitigation from existing members. If so, the non-member will simply join as in Step 1.

Step 3: Enthusiastic actors assess whether they are better off than they would be in the absence of the club. If this is the case, they remain members. If not, they leave the club. ${ }^{63}$ If at least one actor leaves, every actor will reassess whether membership pays off.

\section{Model Results}

Our analysis focuses on the potential for club growth under (1) different (hypothetical) constellations of enthusiastic actors, (2) different scales of the members-only club good and (3) different assumptions about whether conditional commitments are used to induce reluctant actors to join. The dependent variable is club participation measured in terms of members' share of global emissions. The results are presented in Tables 3 (without conditional commitments) and 4 (with conditional commitments), and in Figure 3.

For enthusiastic actors, we consider the world's three biggest emitters individually, every combination of these three, plus the BASIC ${ }^{64}$ and BRICS ${ }^{65}$ groups. These countries with large emissions and economies have the greatest ability to affect global emissions. However, the most vulnerable countries have the greatest interest in reducing global emissions. We therefore also consider what a coalition of the thirty most vulnerable countries (denoted 'Vulnerable 30') might achieve. The Appendix lists this coalition's members. These members have small incomes and low emissions, as shown in Table 2. The results for this coalition will therefore illustrate the potential for small countries to initiate effective co-operation. The model is not well suited to assess clubs accounting for less than 1 per cent of GGP (the logarithmic club-good benefit function would give negative values). Assuming thirty countries act in unison is an optimistic assumption and results in an upper boundary for small countries' potential.

In the baseline runs, Global Damage cost is set to 3 per cent of GGP, and the Vulnerability Weight is set to unity, resulting in the damage-cost distribution across actors shown in Figure 2. While global damages total 3 per cent of GGP, most actors suffer damages greater than 3 per cent of GDP, because GDP and NDGAIN index scores are negatively correlated (that is, small economies

\footnotetext{
${ }^{63}$ Unlike the model analyzed by Weikard (2011), our model permits a club member to withdraw (as Canada did from Kyoto).

64 Brazil, South Africa, India and China.

65 BASIC countries plus Russia.
} 
TA B LE 2 Emissions (Including Land-use Change and Forestry), GDP, and Vulnerability Index Scores of the Ten Largest Emitters and the Group of Thirty Most Vulnerable Countries

\begin{tabular}{lccc}
\hline \hline Actor & \% GHG share & \% GGP share & Vulnerability index \\
\hline China & 27.3 & 12.3 & 0.30 \\
United States & 13.6 & 22.4 & 0.20 \\
EU & 9.0 & 23.2 & 0.20 \\
India & 6.4 & 2.5 & 0.43 \\
Indonesia & 4.8 & 1.2 & 0.34 \\
Russian Federation & 4.7 & 2.8 & 0.29 \\
Japan & 3.1 & 6.5 & 0.29 \\
Brazil & 2.2 & 3.0 & 0.30 \\
Canada & 1.8 & 2.4 & 0.23 \\
Iran, Islamic Rep. & 1.7 & 0.5 & 0.29 \\
Vulnerable 30 & 3.1 & 1.5 & 0.54 \\
\hline \hline
\end{tabular}

Sources: Global Carbon Project 2014 (fossil fuel and cement emissions in 2013); World Resources Institute 2014 (land-use change and forestry emissions in 2011); World Bank 2014 (GDP in 2013 at market exchange rates); Notre Dame Global Adaptation Index 2014 (vulnerability scores for 2012). The vulnerabilities of the EU and 'Vulnerable 30' represent the average of their members' vulnerabilities.

are generally more vulnerable). Alternative values for Global Damage and the Vulnerability Weight are explored below.

The first quadrant of Table 3 explores the scenario with zero club-good provisions and no conditional commitments, that is, where enthusiastic actors have no means of inducing others to join. Three instances of clubs nevertheless persist, because members are better off than they would be without a club. When the $C G B$ Scale is set to 0.1 , all initiating coalitions except one (China alone) persist. Furthermore, China will join all other coalitions of initiators. Because of large emissions and relatively high vulnerability, ${ }^{66}$ it takes relatively little in our model to tip China's cost-benefit calculus in favor of mitigation.

Increasing the CGB Scale from 0.1 to 0.2 doubles the club-good benefit for a given club size. Since it is the largest potential trading partner, the EU is now successful at inducing China, India and Indonesia to join, while the United States successfully induces India and China to join. The BASIC and BRICS coalitions still fail to recruit any reluctant actors.

Increasing the $C G B$ Scale further to 0.25 results in universal membership for all hypothetical enthusiastic-actor coalitions except China alone and the Vulnerable 30. We emphasize that this scenario is rather optimistic; indeed, the club-good benefit will then outweigh the abatement costs of 1 per cent of GDP whenever other members' aggregated GDP exceeds 55 per cent of GGP (see Figure 1). Under these assumptions, the interaction between reluctant actors constitutes an assurance game with multiple equilibria even absent any enthusiastic actors. Note that even under the most optimistic scenario, the Vulnerable 30 manages to recruit only China.

Figure 3 shows participation (measured as the share of global emissions) as a function of CGB scale, with a resolution of 0.01 for the latter. Without conditional commitments, the function is a

66 These two characteristics may be expected to spur China's willingness to engage in climate co-operation generally. Indeed, at COP21 in Paris, other countries' negotiators did not consider that China might potentially block an agreement (personal communications), although its submissions and statements in the negotiation process attempted to set out a hard-line position. 


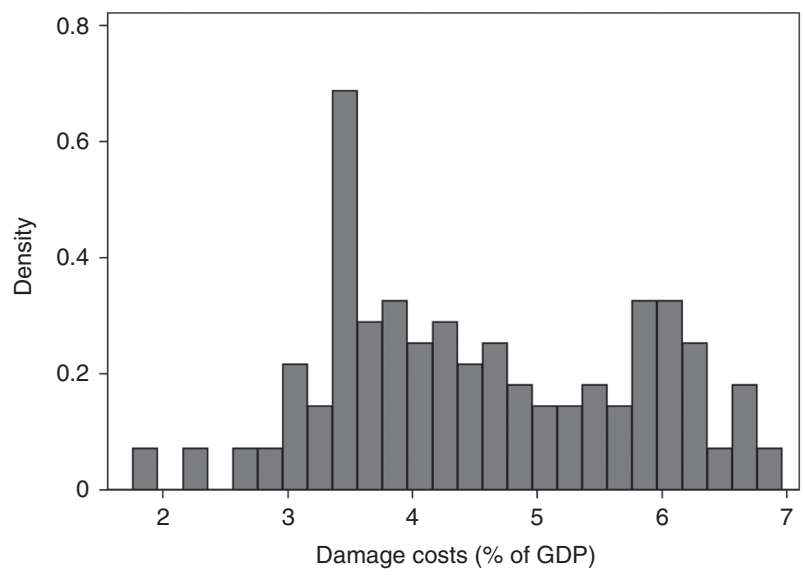

Fig. 2. Histogram of actors' damage costs (\% of GDP) under baseline assumptions

тAвLE 3 Simulated Equilibrium Membership and Emission Coverage (\% of Global Emissions) by Enthusiastic-Actor Constellation and Club-Good Benefit Size

\begin{tabular}{|c|c|c|c|c|}
\hline \multirow[b]{2}{*}{ Enthusiasts } & \multicolumn{2}{|r|}{ No club good } & \multicolumn{2}{|c|}{$C G B$ scale $=0.1$} \\
\hline & $\begin{array}{l}\text { Emissions } \\
\text { covered }\end{array}$ & Members & $\begin{array}{l}\text { Emissions } \\
\text { covered }\end{array}$ & Members \\
\hline China & 0 & None & 0 & None \\
\hline US & 0 & None & 41 & US, China \\
\hline EU & 0 & None & 36 & EU, China \\
\hline China, US & 0 & None & 41 & China, US \\
\hline China, EU & 0 & None & 36 & China, EU \\
\hline US, EU & 0 & None & 50 & China, US, EU \\
\hline China, US, EU & 50 & China, US, EU & 50 & China, US, EU \\
\hline BASIC & 37 & BASIC & 37 & BASIC \\
\hline BRICS & 42 & BRICS & 42 & BRICS \\
\hline Vulnerable 30 & 0 & None & 30 & Vulnerable 30 , China \\
\hline & & $C G B$ scale $=0.2$ & & $C G B$ scale $=0.25$ \\
\hline China & 0 & None & 0 & None \\
\hline US & 47 & China, US, India & 100 & All actors \\
\hline EU & 61 & $\begin{array}{l}\text { China, US, EU, India, } \\
\text { Indonesia }\end{array}$ & 100 & All actors \\
\hline China, US & 47 & China, US, India & 100 & All actors \\
\hline China, EU & 61 & $\begin{array}{l}\text { China, US, EU, India, } \\
\text { Indonesia }\end{array}$ & 100 & All actors \\
\hline US, EU & 61 & $\begin{array}{l}\text { China, US, EU, India, } \\
\text { Indonesia }\end{array}$ & 100 & All actors \\
\hline China, US, EU & 61 & $\begin{array}{l}\text { China, US, EU, India, } \\
\text { Indonesia }\end{array}$ & 100 & All actors \\
\hline BASIC & 37 & BASIC & 100 & All actors \\
\hline BRICS & 42 & BRICS & 100 & All actors \\
\hline Vulnerable 30 & 30 & Vulnerable 30 , China & 30 & Vulnerable 30 , China \\
\hline
\end{tabular}

Note: Vulnerability weight $=1$. Without conditional commitments. 


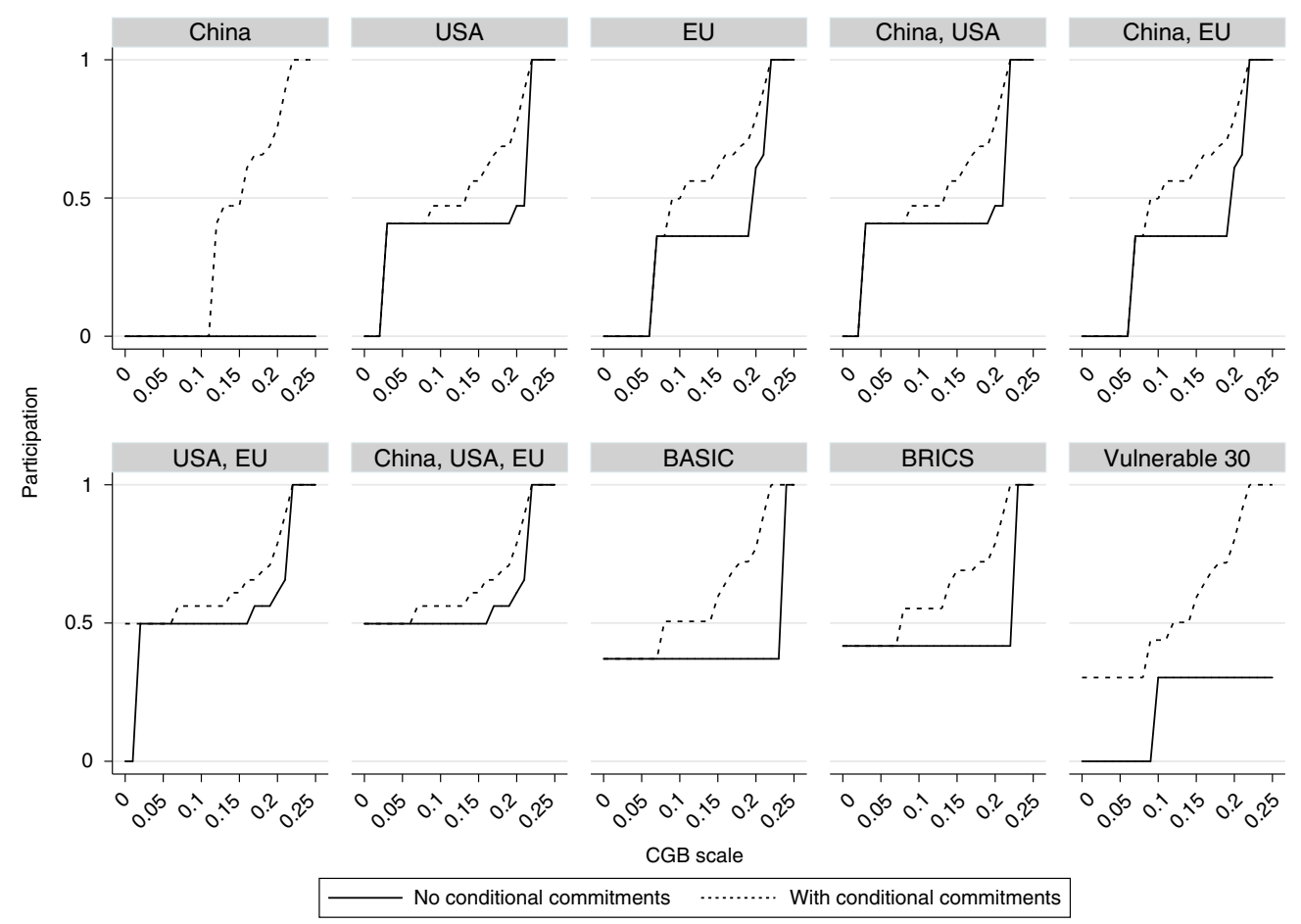

Fig. 3. Participation (share of global emissions contained in the club) as a function of CGB scale, in various scenarios

Note: the header identifies the enthusiasts. Participation refers to the share of global emissions covered (1 denotes 100 per cent).

mix of flat sections and spikes. The spikes may partly be explained by the simple fact that certain individual actors account for a large share of global emissions. However, a more complex dynamic is also at work: cascade effects. When one actor joins, the club-good benefit increases, thereby making it more attractive for other actors to join, too. Many curves display two spikes. The first is caused by a few large reluctant actors joining the club and the second by a cascade including virtually all the others. Because the second spike occurs for CGB Scale values that may be difficult to bring about empirically, the analysis suggests that participation in a club without conditional commitments will be limited to at most a handful of large emitters.

\section{The Effect of Conditional Commitments}

Table 4 shows the simulation results when conditional commitments are permitted. With no club good, conditional commitments prove ineffectual with two exceptions: China will join an EU-US coalition and join the Vulnerable $30 .^{67}$ If the United States or the EU is a lone enthusiast, China will also join; however, the club will collapse, since it is unprofitable to the founder.

Combined with a small (0.1) club good, conditional commitments broaden every club, except the one initiated by China, by attracting either India or the United States. With the intermediate club good (set at 0.2 ), conditional commitments enlarge all coalitions to account for around 80 per cent of global emissions. Finally, combined with the largest club good (0.25), conditional

${ }^{67}$ The latter coalition barely manages to recruit China; the 25 most vulnerable countries would fail. 
TABLE 4 Simulated Equilibrium Membership and Emission Coverage (\% of Global Emissions) by Enthusiastic-Actor Constellation and Club-Good Benefit Size

\begin{tabular}{|c|c|c|c|c|}
\hline \multirow[b]{2}{*}{ Enthusiasts } & \multicolumn{2}{|c|}{ No club good } & \multicolumn{2}{|c|}{$C G B$ scale $=0.1$} \\
\hline & $\begin{array}{l}\text { Emissions } \\
\text { covered }\end{array}$ & Members & $\begin{array}{c}\text { Emissions } \\
\text { covered }\end{array}$ & Members \\
\hline China & 0 & None & 0 & None \\
\hline US & 0 & None & 47 & US, China, India \\
\hline EU & 0 & None & 50 & China, US, EU \\
\hline China, US & 0 & None & 47 & China, US, India \\
\hline China, EU & 0 & None & 50 & China, US, EU \\
\hline US, EU & 50 & China, US, EU & 56 & China, US, EU, India \\
\hline China, US, EU & 50 & China, US, EU & 56 & China, US, EU, India \\
\hline BASIC & 37 & BASIC & 51 & BASIC, US \\
\hline BRICS & 42 & BRICS & 55 & BRICS, US \\
\hline \multirow[t]{2}{*}{ Vulnerable 30} & 30 & Vulnerable 30, China & 44 & $\begin{array}{c}\text { Vulnerable } 30, \\
\text { China, US }\end{array}$ \\
\hline & & $C G B$ scale $=0.2$ & & $C G B$ scale $=0.25$ \\
\hline China & 76 & 11 actors & 100 & All actors \\
\hline US & 77 & 12 actors & 100 & All actors \\
\hline EU & 79 & 13 actors & 100 & All actors \\
\hline China, US & 77 & 12 actors & 100 & All actors \\
\hline China, EU & 79 & 13 actors & 100 & All actors \\
\hline US, EU & 79 & 13 actors & 100 & All actors \\
\hline China, US, EU & 79 & 13 actors & 100 & All actors \\
\hline BASIC & 77 & 12 actors & 100 & All actors \\
\hline BRICS & 79 & 13 actors & 100 & All actors \\
\hline Vulnerable 30 & 80 & 42 actors & 100 & All actors \\
\hline
\end{tabular}

Note: Vulnerability weight $=1$. Without conditional commitments.

commitments ensure universal participation in both scenarios where this is not achieved already. Across all runs, enthusiasts' expenditures on conditional commitments equal 0.1 per cent-1.2 per cent of GDP. In addition to broadening participation, these commitments cause a moderate deepening of co-operation.

Figure 3 shows that conditional commitments are particularly effective at broadening participation for $C G B$ Scale values between the two spikes identified above. Conditional commitments smoothen the participation curve for two reasons. First, they effectively broaden participation from including only the top three to five emitters to also include other top fifteen emitters; each new emitter represents an incremental increase in the share of global emissions covered by the club. Secondly, while club growth means that more and more actors offer conditional commitments, cascade effects are moderated because each actor's marginal mitigation costs increase with the mitigation level, as captured in the quadratic cost function. Overall, conditional commitments appear to produce a substantial increase in club participation even when combined with only moderate levels of club-good benefits.

\section{Sensitivity to Assumptions on Damage Cost Magnitude and Distribution}

The online appendix (Section 5) analyses the main results' sensitivity to alternative assumptions concerning the size of the damage costs (Global Damage Cost) and distribution (Vulnerability 
Weight). Rerunning the model with Global Damage Cost 50 per cent lower than the baseline yields little co-operation except when the club-good benefit is large. Conversely, setting Global Damage Cost 50 per cent higher than the baseline increases participation in most scenarios and does not reduce it in any. While these results are both intuitive and consistent with observations of how individuals act in co-operation game experiments, ${ }^{68}$ they contradict certain game-theoretic predictions concerning treaty participation. ${ }^{69}$ Another effect of increasing Global Damage Cost is enhancing the effectiveness of conditional commitments, and thus somewhat reducing the need for club-good benefits because the higher marginal returns from co-operation increase the leverage of conditional commitments.

Varying the value of Vulnerability Weight results in smaller changes than those obtained when varying Global Damage Cost, indicating that for participation rates, the mean damage cost matters more than the variance. Changing Vulnerability Weight has a non-linear effect on participation, and the sign of this effect depends on who the enthusiasts are.

\section{Including Non-climate Relations}

Our baseline model omits all relationships outside the climate change mitigation domain. While useful for a transparent first assessment of clubs' potential, this simplification ignores the complexity of international relations. We now explore the extent to which our results change when we include the political costs and benefits derived from actors' bilateral relationships concerning trade, similarity of policy preference expressed in voting in the United Nations General Assembly (UNGA), and militarized interstate disputes (MID). We limit this analysis to relations among the top ten emitters, which have emerged as the main drivers of our results thus far.

Strong trade relations may increase the likelihood of climate co-operation. We implement such a relationship by making the club-good benefit a function of a country's trade with other members. Figures 4 and 5 present the results when Equation 2 is modified by replacing $G D P_{m}$ with the share of $i$ 's total trade (imports plus exports) that flows to or from member $m$. The Appendix offers further methodological details. Figures 4 and 5 show that the changes relative to our baseline results are few, negative and mostly small (see the 'With trade' column). The reason they are negative is that, in our data, trade flows are somewhat more dispersed than GDP is, so the largest economies are less dominant than in the baseline - and hence less effective at attracting new club members.

Countries interact in many other issue areas as well, some which will likely involve functional linkages to - or be considered as more pressing than - climate change. In such instances, concerns other than climate change may well influence decisions concerning climate clubs. For example, when the United States and many other countries imposed economic sanctions on Iran to compel its government to refrain from developing nuclear weapons, offering Iran preferential market access in return for joining a particular climate club would probably not be considered appropriate. More generally, we assume that countries are inclined to treat 'friends' better than 'enemies', other things being equal.

To explore how this inclination might affect our results, we include political benefits derived from bivariate affinity and political costs derived from bilateral conflict relationships for the world's ten largest GHG emitters. We measure affinity as similarity of voting records in the

68 Ambrus and Pathak 2011.

${ }^{69}$ In particular, our result contradicts the prediction that a positive shift in the cost of making a contribution will cause the level of co-operation to increase (Barrett 2003 and elsewhere). Experimental results also lend very little support to this prediction (e.g., Helland and Hovi 2008). 


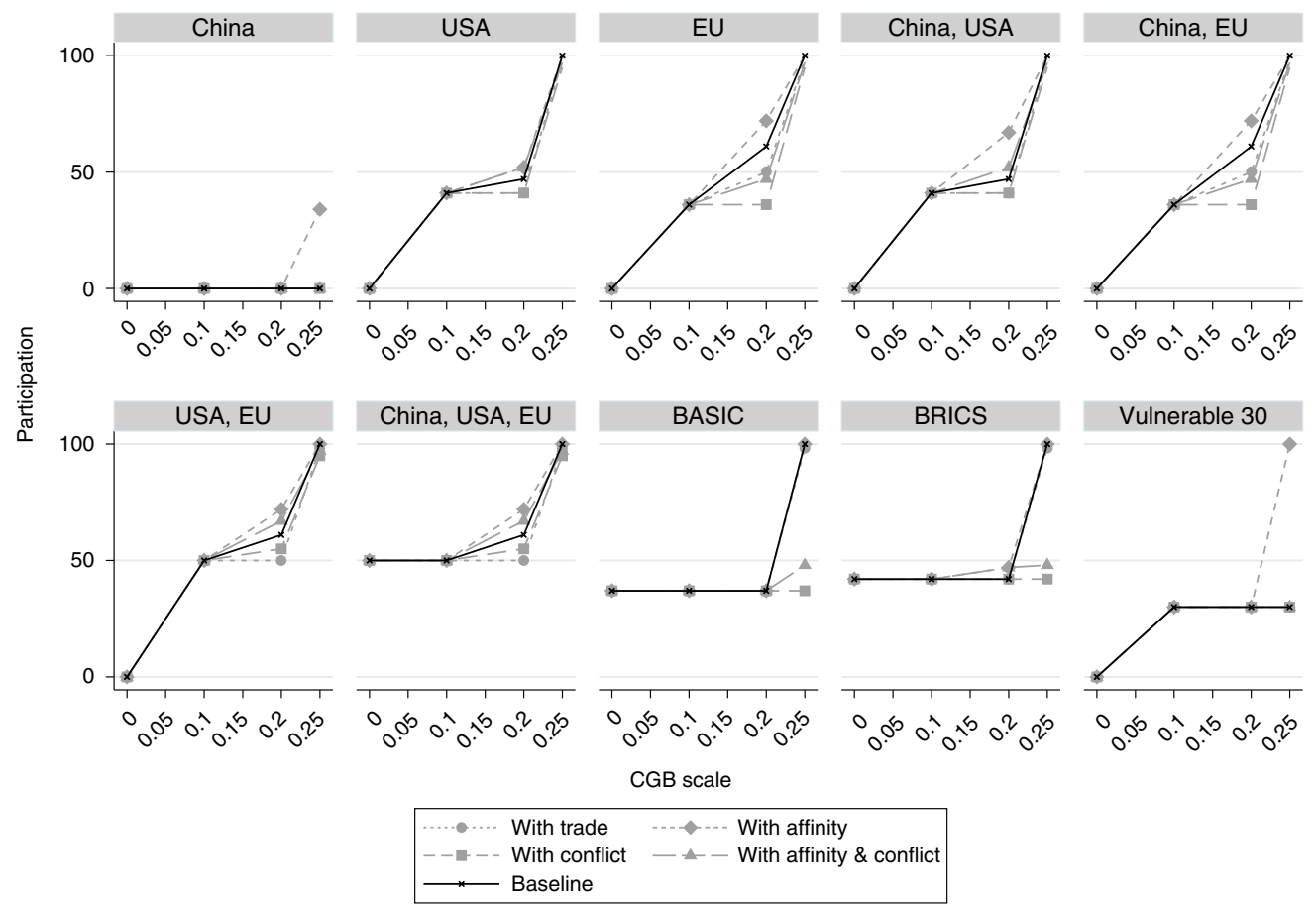

Fig. 4. Sensitivity of simulated participation (\% of global emissions), without conditional commitments

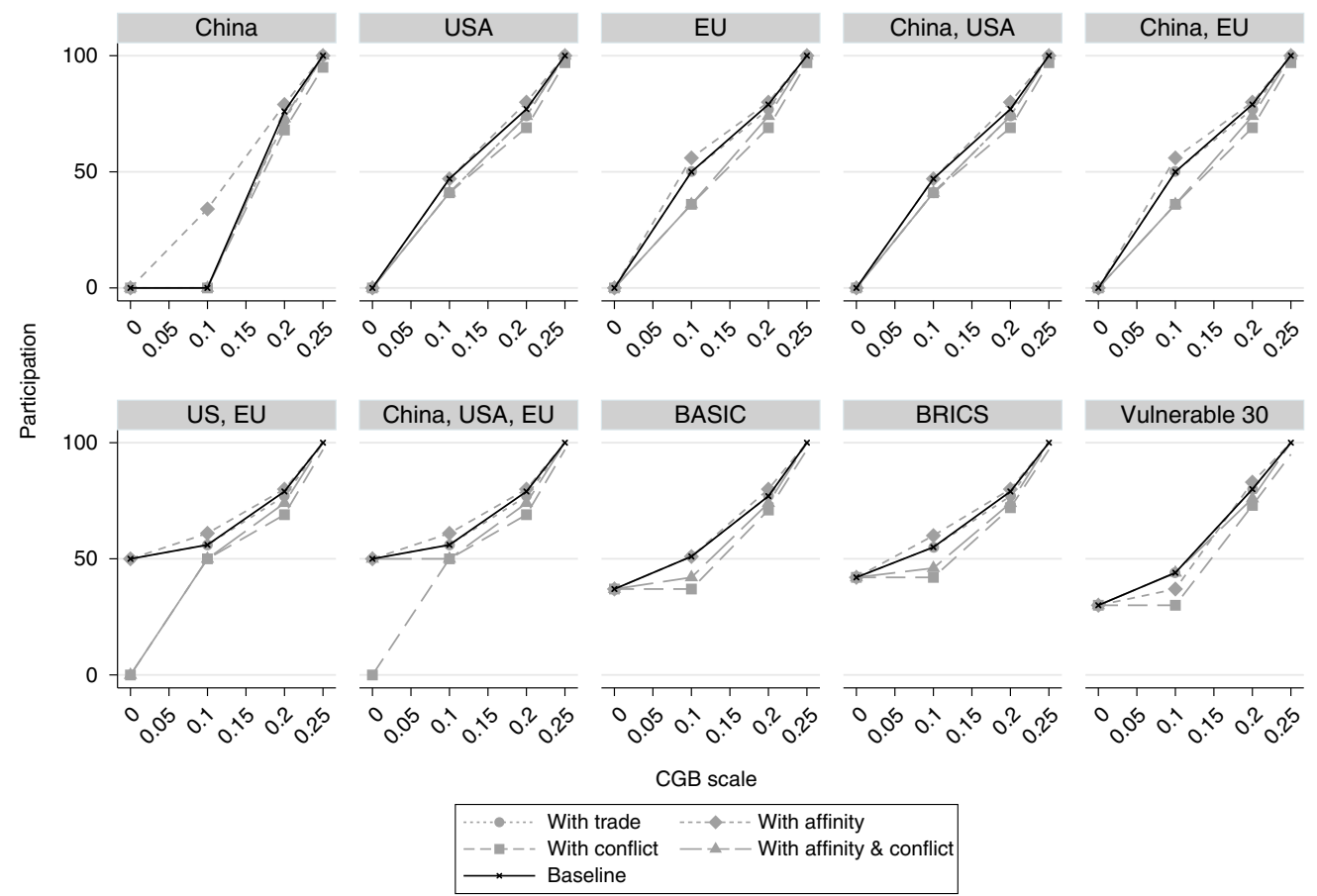

Fig. 5. Sensitivity of simulated participation (\% of global emissions), with conditional commitments 
UNGA during the 2005-14 period. We measure conflict as involvement in MIDs with other main emitters during the 2001-10 decade. We model affinity and conflict by adding a separate estimate of political benefits and the costs of membership. The Appendix explains how we identified twenty-one affinity relations and ten MIDs among the top ten emitters. The relative weights of affinity and conflict are set so that the weighted sum of estimated positive and negative costs equals zero. The weight given to this political calculus relative to other costs and benefits is set (somewhat arbitrarily) so that the club-good benefit increases by 0.1 per cent of GDP for every 'friendly' member and declines by $0.16-0.24$ per cent of GDP for every 'enemy' member. These political costs and benefits influence outsiders' decisions about joining both directly and indirectly (via insiders' willingness to offer conditional commitments).

Figures 4 and 5 show that including affinity alone has limited effects. Including conflict alone has somewhat larger effects, mainly because China has had conflicts with the United States and India. Particularly, deals based on conditional commitments between the major emitters suffer, as seen for $C G B=0.1$. Another change is that Iran is left out even under the most optimistic club-good benefit assumption. When both affinity and conflict are included, conflict mostly dominates.

Overall, the main results from our baseline model appear to be robust to the inclusion of bilateral relations outside of climate change. While some point predictions change, the general pattern persists. Because the more complex model considerably increases data requirements and complexity, particularly if extended to all actors, the simpler baseline model seems generally preferable. The effect of including such bilateral relations would increase if these relations were given greater weight in the cost-benefit calculus. Anecdotal evidence suggests, however, that climate co-operation in the presence of conflict (MIDs) is indeed possible and may even make a real difference. For example, China and the United States announced their new mitigation targets to the UNFCCC as part of a bilateral agreement, ${ }^{70}$ and China and India work through the same UNFCCC negotiation blocs.

\section{Summary of Results}

We summarize our main results in eight points. First, with no conditional commitments, universal participation emerges only under very optimistic assumptions concerning the club-good benefits a climate club can produce.

Secondly, more modest club-good benefits enable some constellations of enthusiastic actors to persist and to induce other top five emitters to join. Hence, if club goods can be provided, the prospects for club emergence increase substantially.

Thirdly, without any club good, conditional commitments are effective only under a limited set of conditions. Hence, Weischer, Morgan and Patel's condition that club success requires club-good benefits largely holds (albeit with a few important exceptions). ${ }^{71}$

Fourthly, under a range of conditions, the combination of club-good benefits and conditional commitments facilitates clubs covering the majority of global emissions. Conditional commitments effectively enhance co-operation in the presence of club-good benefits and vice versa.

Fifthly, enthusiasm from the United States and the EU greatly increases a club's prospects. Enthusiasm (as defined in the model) from China is less necessary, because China's strong self-interest in mitigation makes it easier to entice it. Tipping China's own cost-benefit ratio in favor of mitigation seems to be the only chance small countries have to initiate a viable club.

${ }^{70}$ See Goodell 2014.

${ }^{71}$ Weischer, Morgan, and Patel 2012. 
However, that would require a large number of them to act jointly, and would lead to further club growth only under optimistic assumptions about club-good benefits.

Sixthly, higher marginal returns from co-operation (captured through the Global Damage Costs parameter) tend to increase participation.

Seventhly, our results also indirectly explain why existing club-like arrangements have been no more effective than the UNFCCC has been in mitigating climate change. These clubs neither provide exclusive benefits for members nor make conditional commitments to further reduce their emissions if reluctant countries join. They might nevertheless serve other useful functions, such as coordinating diplomatic initiatives or creating a conducive setting for raising political awareness and enhancing political legitimacy across conventional political divides. In a world torn by huge asymmetries between rich and poor and by strong competition in global markets and international politics, these would be non-trivial achievements. Yet such contributions are a far cry from the kind of powerful climate club action considered in this article.

Finally, our main results seem reasonably robust. Including the political costs and benefits derived from bilateral relationships concerning trade, voting affinity in the UNGA and militarized conflicts has only a moderate bearing on them. Likewise, increasing or decreasing the variance of actors' vulnerability does not alter the aforementioned seven results. However, increasing or decreasing such variance sometimes changes which actors become club members and affects the abatement cost distribution.

\section{CONCLUSIONS}

Overall, our results support Victor's advice to build on what enthusiastic and powerful nations are willing and able to contribute. In particular, these results suggest that if one or more major economies were willing to lead and to use a combination of significant club-good benefits and conditional commitments, there would be substantial potential to induce reluctant actors to follow suit.

Our results also provide additional insights that would be hard to reach through theoretical reasoning alone. For example, we find that if used separately, club goods and conditional commitments are effective only under a restricted set of favorable conditions. By contrast, in combination they are effective in a much broader set of circumstances.

A particularly interesting finding concerns the potential role of conditional commitments in reducing GHG emissions. Climate change mitigation is a quintessential collective action problem. Thus the benefits produced through ambitious actors' mitigation efforts cannot be withheld from reluctant actors. However, credible conditional commitments by enthusiastic actors with high levels of emissions can change a reluctant country's cost-benefit balance both by reducing its indirect costs of climate action and by increasing the climate benefits of its mitigation efforts (through triggering additional mitigation efforts by others). Since the overarching purpose of a climate club is to provide a pure public good, the members will benefit from a broadening membership. Moreover, since the actors most likely to respond positively to current club members' conditional commitments will probably share the founding members' general concerns about the impact of climate change, agreement on how much each actor will contribute to mitigation efforts should be easier to reach in a club setting than in the context of UNFCCC global conference diplomacy. A climate club can also circumvent the least-ambitious-party logic of the UNFCCC; in particular, it can implement ambitious climate mitigation without having to obtain the consent of the UNFCCC's most reluctant parties. 


\section{Model Fit with the 'Real World'}

Our ABM provides an innovative and empirically grounded formalization of climate club dynamics. Nevertheless, modeling involves simplification, and some of the conditions for climate clubs to emerge and grow posited by our ABM are not currently met in the real world. ${ }^{72}$ Readers are therefore advised to interpret our results as indicating the prospects for effective club-based climate change mitigation under relatively favorable conditions. Below we call attention to four assumptions that, at least when seen together, tend to underestimate the challenges of developing effective climate clubs.

One is the assumption of no carbon leakage (see footnote 48). In the real world, the risk of carbon leakage will vary with, inter alia, the size and composition of the club. At the founding stage, some industry and business companies in the few countries involved may well be tempted to take advantage of lower taxes or other privileges in non-member countries. If the club grows, such temptations will in most instances decline. Yet by not incorporating carbon leakage as a possibility, our model seems overly optimistic, at least with regards to the founding stage. In further development of our model, this bias calls for attention.

Secondly, our model assumes that all conditional commitments are fully credible and instantaneously actionable. This assumption is no doubt overly bold, and since credibility is vital for conditional commitments to work, plausible modifications could further enhance the model's real-world relevance.

Thirdly, our model assumes there are no problems concerning compliance. While this assumption seems plausible for enthusiastic countries, reluctant country members might be expected to drag their feet in fulfilling their membership requirements. If so, the enthusiastic countries may incur additional costs.

Finally, while we model countries - and the EU - as unitary actors, some of the greatest impediments to international co-operation are created by the interaction between domestic and international political processes. ${ }^{73}$ Further model refinements could explicitly include aspects of domestic politics, for example the roles of veto players and winning coalitions.

To balance the picture, we should add that a couple of our other assumptions likely err on the side of caution. One of these assumptions says that climate change mitigation will have no (positive) side effects for the country involved. This is not correct; in several countries, for example in China, positive side effects (co-benefits) sometimes seem to be the main driver of mitigation measures. Our main model also assumes that neither friendship nor hostility affects countries' willingness to co-operate with each other in a climate club context. However, our sensitivity tests indicate that at least involvement in military disputes can make a difference. Another study, focusing on the field of international political economy, reports that cultural similarity is 'consistently important in explaining policy choice'. ${ }^{74}$

\section{Other Potential Extensions}

Several other extensions and refinements could help further improve the model as a research tool. First, the model does not include adaptation to climate change. We believe that clubs can also contribute as tools for enhancing adaptation, but the results reported here cannot be generalized beyond mitigation.

72 Nordhaus 2015.

73 Mayer 1992; Putnam 1988.

74 Simmons and Elkins 2004, 186. 
Secondly, we do not incorporate timing into the estimates of damage costs and abatement costs. Damage costs will likely become greater the longer it takes to address emissions, while abatement costs may fall over time as a result of technological developments. If so, clubs that fail to form initially may become viable later.

Thirdly, our notions of costs and benefits might be further developed to include, for example, transaction and transition costs or indirect effects more generally.

Fourthly, most policy makers and stakeholders care about distributive (and procedural) fairness. ${ }^{75}$ The model could be extended to include fairness principles by, for example, treating norms as 'filters' excluding policy options that clearly fail to meet one or more of these principles. $^{76}$

Fifthly, game-theoretic models suggest that side payments can drastically increase mitigation when actors are strongly asymmetric. ${ }^{77}$ In contrast to conditional commitments, side payments work by offering benefits exclusively to potential entrants. An extension of the model therefore considers side payments. ${ }^{78}$

Sixthly, trade restrictions constitute another potential instrument for incentivizing membership. Nordhaus ${ }^{79}$ finds that import tariffs can sustain an equilibrium with high levels of co-operation. However, as mentioned above, he does not model club growth. We find that positive trade incentives can facilitate club growth. It seems plausible that negative trade incentives could do so, too; however, further studies are required to establish whether this intuition is warranted.

Finally, the kind of analysis reported here may provide inputs to further refinement of general club theory. In particular, it may serve as a basis to further clarify the relationship between the goods provided by voluntary clubs and the instruments available for recruiting new members. As indicated above, the role of conditional commitments in enhancing the supply of public goods will depend on - among other things - the exact nature of these goods. ${ }^{80}$ This line of reasoning could be extended to, for example, further analysis of the interplay between club goods, conditional commitments and side payments in alternative club settings.

\section{REFERENCES}

Ambrus, Attila, and Parag A. Pathak. 2011. Cooperation Over Finite Horizons: A Theory and Experiments. Journal of Public Economics 95 (7):500-12.

Andresen, Steinar. 2014. Exclusive Approaches to Climate Governance: More Effective than the UNFCCC? In Toward a New Climate Agreement, edited by Todd L. Cherry, Jon Hovi and David M. McEvoy, 155-66. London: Routledge.

Barrett, Scott. 2003. Environment and Statecraft: The Strategy of Environmental Treaty-Making. Oxford: Oxford University Press.

- 2013. Climate Treaties and Approaching Catastrophes. Journal of Environmental Economics and Management 66 (2):235-50.

Böhringer, Christoph, Carolyn Fischer, and Knut Einar Rosendahl. 2010. The Global Effects of Subglobal Climate Policies. The BE Journal of Economic Analysis \& Policy 10 (2):Article 13.

Buchanan, James M. 1965. An Economic Theory of Clubs. Economica 32 (1):1-14.

75 Dannenberg, Sturm, and Vogt 2010.

76 Underdal and Wei 2015.

77 Barrett 2003.

78 Sælen 2016.

79 Nordhaus 2015.

80 Olson 1965. 
Buchholz, Wolfgang, Christian Haslbeck, and Todd Sandler. 1998. When Does Partial Cooperation Pay? Finanzarchiv 55 (1):1-20.

Buchner, Barbara, Carlo Carraro, and Igor Cersosimo, and Carmen Marchiori. 2005. Back to Kyoto? US Participation and the Linkage Between R\&D and Climate Cooperation. In The Coupling of Climate and Economic Dynamics: Essays on Integrated Assessment, edited by Alain Haurie and Laurent Viguier, 173-204. Berlin: Springer Verlag.

Carraro, Carlo, and Domenico Siniscalco. 1997. R\&D Cooperation and the Stability of International Environmental Agreements. In International Environmental Agreements: Strategic Policy Issues, edited by Carlo Carraro, 71-96. Cheltenham: Edward Elgar.

Clarke, Leon, Kejun Jiang, Keigo Akimoto, Mustafa Babiker, Geoffrey Blanford, Karen Fisher-Vanden, Jean-Charles Hourcade, Volker Krey, Elmar Kriegler, Andreas Löschel, David McCollum, Sergey Paltsev, Steven Rose, Priyadarshi R. Shukla, Massimo Tavoni, Bob van der Zwaan, and Detlef P. van Vuuren. 2014. Assessing Transformation Pathways. In Climate Change 2014: Mitigation of Climate Change. Contribution of Working Group III to the Fifth Assessment Report of the Intergovernmental Panel on Climate Change, edited by Ottmar Edenhofer, Ramón Pichs-Madruga and Youba Sokona, 413-510. Cambridge, UK: Cambridge University Press.

Dannenberg, Astrid, Bodo Sturm, and Carsten Vogt. 2010. Do Equity Preferences Matter for Climate Negotiators? An Empirical Investigation. Environmental and Resource Economics 47 (1):91-109.

d'Aspremont, Claude, Alexis Jacquemin, Jean Jaskold Gabszewicz, and John A. Weymark. 1983. On the Stability of Collusive Price Leadership. Canadian Journal of Economics 16 (1):17-25.

DeSombre, Elizabeth R. 1995. Baptists and Bootleggers for the Environment: The Origins of United States Unilateral Sanctions. Journal of Environment and Development 4 (Winter):53-75.

Falkner, Robert. 2016. A Minilateral Solution for Global Climate Change? On Bargaining Efficiency, Club Benefits and International Legitimacy. Perspectives on Politics 14 (1):87-101.

Finus, Michael. 2003. Stability and Design of International Environmental Agreements: The Case of Transboundary Pollution. In The International Yearbook of Environmental and Resource Economics 2003/2004: A Survey of Current Issues, edited by Henk Folmer and Tom Tietenberg, 82-158. Cheltenham: Edward Elgar.

Francois, Joseph, Miriam Manchin, Hanna Norberg, Olga Pindyuk, and Patrick Tomberger. 2013. Reducing Transatlantic Barriers to Trade and Investment: An Economic Assessment. Institute for International and Development Economics. Available from http://trade.ec.europa.eu/doclib/docs/ 2013/march/tradoc_150737.pdf, accessed 22 February 2017.

Gampfer, Robert. 2016. Minilateralism or the UNFCCC? The Political Feasibility of Climate Clubs. Global Environmental Politics 16 (3):62-88.

Gardoqui, Beatriz Leycegui, and Imanol Ramírez. 2015. Addressing Climate Change: A WTO Exception to Incorporate Climate Clubs. Geneva: International Centre for Trade and Sustainable Development. Available from http://e15initiative.org/publications/wto-exception-to-incorporate-climate-clubs/, accessed 2 May 2017.

Global Carbon Project. 2014. Fossil Fuel and Cement Emissions 2013. Available from http://www. globalcarbonatlas.org/?q=en/emissions, accessed 1 October 2014.

Goodell, Jeff. 2014. The Secret Deal to Save the Planet: Inside the High-Stakes Drama Behind Obama's China Climate Talks. Rolling Stone, 9 December. http://www.rollingstone.com/politics/news/thesecret-deal-to-save-the-planet-20141209, accessed 22 February 2017.

Helland, Leif, and Jon Hovi. 2008. Renegotiation Proofness and Climate Agreements: Some Experimental Evidence. Nordic Journal of Political Economy 34 (2):1-26.

Helm, Dieter, Cameron Hepburn, and Giovanni Ruta. 2012. Trade, Climate Change, and the Political Game Theory of Border Carbon Adjustments. Oxford Review of Economic Policy 28 (2):368-94.

Hoel, Michael. 1991. Global Environmental Problems: The Effects of Unilateral Actions Taken by One Country. Journal of Environmental Economics and Management 20 (1):55-70.

2012. Klimapolitikk og Lederskap: Hvilken Rolle Kan et Lite Land Spille? Report No. 2012/05, Vista Analyse. 
Holtsmark, Bjart. 2013. International Cooperation on Climate Change: Why is There So Little Progress? In Handbook on Energy and Climate Change, edited by Roger Fouquet, 327-43. Cheltenham: Edward Elgar.

Hovi, Jon, Detlef F. Sprinz, Håkon Sælen, and Arild Underdal. 2016. Climate Change Mitigation: A Role for Climate Clubs? Palgrave Communications. doi:10.1057/palcomms.2016.20.

Hovi, Jon, Hugh Ward, and Frank Grundig. 2015. Hope or Despair? Formal Models of Climate Cooperation. Environmental and Resource Economics 63 (4):665-88.

Iyer, Gokul C., Leon E. Clarke, James A. Edmonds, Brian P. Flannery, Nathan E. Hultman, Haewon C. McJeon, and David G. Victor. 2015. Improved Representation of Investment Decisions in Assessments of $\mathrm{CO}_{2}$ Mitigation. Nature Climate Change 6 (5):436-40.

Keohane, Nathaniel, Annie Petsonk, and Alex Hanafi. 2015. Toward a Club of Carbon Markets. Climatic Change.

Lipson, Charles. 1981. The International Organization of Third World Debt. International Organization 35 (4):603-631.

Mattoo, Aaditya, and Arvind Subramanian. 2012. Equity in Climate Change: An Analytical Review. World Development 40 (6):1083-097.

Mayer, Frederick W. 1992. Managing Domestic Differences in International Negotiations: The Strategic Use of Internal Side-Payments. International Organization 46 (4):793-818.

Miller, John H., and Scott E. Page. 2007. Complex Adaptive Systems: An Introduction to Computational Models of Social Life. Princeton, NJ: Princeton University Press.

Morgan, Jennifer, Dirk Messner, and Hans Joachim Schellnhuber. 2014. A Renewables Club to Change the World. Available from http://www.wri.org/blog/2014/05/renewables-club-change-world, accessed 2 May 2017.

Nordhaus, William. 2015. Climate Clubs: Overcoming Free-Riding in International Climate Policy. American Economic Review 105 (4):1339-370.

Notre Dame Global Adaptation Index. 2014. Vulnerability Scores for 2012. Available from http://index. gain.org/about/download, accessed 7 April 2014.

Olson, Mancur. 1965. The Logic of Collective Action. Cambridge, MA: Harvard University Press.

Prakash, Aseem, and Matthew Potoski. 2007. Collective Action Theory Through Voluntary Environmental Programs: A Club Theory Perspective. The Policy Studies Journal 35 (4):773-92.

Putnam, Robert D. 1988. Diplomacy and Domestic Politics: The Logic of Two-Level Games. International Organization 42 (3):427-460.

Richter, Andries, and Johan Grasman. 2013. The Transmission of Sustainable Harvesting Norms When Agents are Conditionally Cooperative. Ecological Economics 93 (1):202-09.

Sælen, Håkon. 2014. The Effect of Enforcement in the Presence of Strong Reciprocity: An Application of Agent-Based Modeling. In Toward a New Climate Agreement, edited by Todd L. Cherry, Jon Hovi and David M. McEvoy, 233-53. London: Routledge.

—. 2016. Side-Payments: An Effective Instrument for Building Climate Clubs? Side-Payments: An Effective Instrument for Building Climate Clubs? International Environmental Agreements 16 (6): 909-32.

Shum, Robert Y. 2014. China, the United States, Bargaining, and Climate Change. International Environmental Agreements 14 (1):83-100.

Simmons, Beth A., and Zachary Elkins. 2004. The Globalization of Liberalization: Policy Diffusion in the International Political Economy. American Political Science Review 98 (1):171-89.

Sprinz, D. and T. Vaahtoranta, 1994. The Interest-Based Explanation of International Environmental Policy. International Organization 48 (1):77-105.

Stavins, Robert, Zou Ji, Thomas Brewer, Mariana Conte Grand, Michel den Elzen, Michael Finus, Joyeeta Gupta, Niklas Höhne, Myung-Kyoon Lee, Axel Michaelowa, Matthew Paterson, Kilaparti Ramakrishna, Gang Wen, Jonathan Wiener, and Harald Winkler. 2014. International Cooperation: Agreements and Instruments. In Mitigation of Climate Change. Contribution of Working Group III to the Fifth Assessment Report of the Intergovernmental Panel on Climate Change, edited by Ottmar Edenhofer, Ramón Pichs-Madruga and Youba Sokona. Cambridge: Cambridge University Press. 
Stern, Nicholas. 2007. The Economics of Climate Change: The Stern Review. Cambridge, UK: Cambridge University Press.

Sterner, Thomas, Jared Carbone, and Carolyn Fischer. 2015. The Net Emissions Effects of Fuel Taxes. Green Growth Knowledge Platform. Third Annual Conference, 29-30 January. Available from http://www.greengrowthknowledge.org/sites/default/files/Sterner_The_net_emissions_effects_of_fuel_ taxes.pdf, accessed 15 April 2015.

Stewart, Richard B., Michael Oppenheimer, and Bryce Rudyk. 2013a. Building Blocks for Global Climate Protection. Stanford Environmental Law Journal 32 (2):12-43.

- 2013bA New Strategy for Global Climate Protection. Climatic Change 120 (1-2):1-12.

Stiglitz, Joseph E. 2006. A New Agenda for Global Warming. The Economist's Voice 3 (7):26-27.

Underdal, Arild. 2010. Complexity and Challenges of Long-Term Environmental Governance. Global Environmental Change 20 (3):386-93.

Underdal, Arild, Jon Hovi, Steffen Kallbekken, and Tora Skodvin. 2012. Can Conditional Commitments Break the Climate Change Negotiations Deadlock? International Political Science Review 33 (4): 475-493.

Underdal, Arild, and Taoyuan Wei. 2015. Distributive Fairness: A Mutual Recognition Approach. Environmental Science and Policy 51:35-44.

UNFCCC. 2015. Synthesis Report on the Aggregate Effect of the Intended Nationally Determined Contributions. Note by the Secretariat. FCCC/CP/2015/7. Available from http://unfccc.int/resource/ docs/2015/cop21/eng/07.pdf.

Victor, David G. 2011. Global Warming Gridlock: Creating More Effective Strategies for Protecting the Planet. Cambridge: Cambridge University Press.

Weikard, Hans-Peter. 2011. Toward a Global Climate Constitution. In Institutionen ökologischer Nachhaltigkeit. Normative und institutionelle Grundfragen der Ökonomik; Jahrbuch 9, edited by Martin Held, Gisela Kubon-Gilke and Richard Sturn, 89-106. Marburg, Germany: Metropolis.

Weischer, Lutz, Jennifer Morgan, and Milap Patel. 2012. Climate Clubs: Can Small Groups of Countries Make a Big Difference in Addressing Climate Change? Review of European Community and International Environmental Law (RECIEL) 21 (3):177-92.

World Bank. 2014. GDP 2013 (Constant 2005 US\$). Available from http://databank.worldbank.org/data/ views/variableselection/selectvariables.aspx?source=world-development-indicators\#s_cbudsjet, accessed 1 October 2014.

World Resources Institute. 2014. CAIT 2.0 Total GHG Emissions from Land-Use Change and Forestry 2011. Available from http://cait2.wri.org/wri/Country\%20GHG\%20Emissions, accessed 1 October 2014. 